\title{
A longitudinal analysis of mental and general health status of informal carers in Australia
}

\author{
Itismita Mohanty $^{1^{*}}$ (D) and Theo Niyonsenga ${ }^{1,2}$
}

\begin{abstract}
Background: The study investigated the self-assessed mental and general health status of informal carers in Australia. It evaluated the influence of carer's health behaviours, namely physical activity, smoking and drinking status, along with their social connectedness and workforce engagement on their health status.

Methods: The study used a retrospective longitudinal design using data from the Household Income and Labour Dynamics of Australia survey, waves 5-15 (2005-2015). It included individuals aged 15 years and older from Australian households surveyed over a period of 11 years. The sample consisted of 23,251 individuals. The outcome measures included: mental health, general health and physical functioning domains of the Short Form 36 Questionnaire, a widely used multi-dimensional measure of health-related quality of life. Using fixed effects regression and following individuals over time, the analysis took care of the issue of individuals self-selecting themselves as carers due to some predisposing factors such as age, poor health, socioeconomic status and sedentary behaviour.
\end{abstract}

Results: There were statistically significant carer-noncarer status differences in mental (Beta $=-0.587, p=0.003$ ) and general health (Beta $=-0.670, p=0.001$ ) outcomes. Aging had a modifying impact on carers' mental and general health outcomes. Older carers coped better with their caregiving responsibilities than younger ones. Moreover, while physical activities had a positive influence on both mental and general health for non-carers, with more activities generating better health outcomes, it only had a modifying impact on carers' mental health. Furthermore, the study found that moderate levels of social drinking had beneficial modifying impact on carers' mental and general health.

Conclusion: This study added value to the literature on informal carers' mental and general health in Australia by identifying some of the protective and risk factors. The study found the modifying effects of carers' age, health behaviours such as physical activity, smoking and drinking status on their health. Finally, the study identified an apparent beneficial link between moderate levels of social drinking and carer health that needs to be further explored with more targeted future research.

Keywords: Informal carers health, Mental health, General health, Health behaviour and informal carers age

\footnotetext{
* Correspondence: itismita.mohanty@canberra.edu.au

${ }^{1}$ Health Research Institute, Faculty of Health, University of Canberra, Canberra,

Australian Capital Territory 2617, Australia

Full list of author information is available at the end of the article
}

(c) The Author(s). 2019 Open Access This article is distributed under the terms of the Creative Commons Attribution 4.0 International License (http://creativecommons.org/licenses/by/4.0/), which permits unrestricted use, distribution, and reproduction in any medium, provided you give appropriate credit to the original author(s) and the source, provide a link to the Creative Commons license, and indicate if changes were made. The Creative Commons Public Domain Dedication waiver (http://creativecommons.org/publicdomain/zero/1.0/) applies to the data made available in this article, unless otherwise stated. 


\section{Introduction}

Informal carers are those who have a main role providing care for someone, closely related to them, a friend or a neighbour, primarily in the home environment or outside with a range of physical, mental and end-of-life health conditions, and disability $[1,2]$. They make a significant contribution to the care and wellbeing of people with a disability, mental illness, chronic condition, terminal illness and the elderly. In 2015, over 1 in 8 Australians (2.86 million) were estimated to be providing informal care, which was estimated to have a replacement value of $\$ 60.3$ billion, equivalent to $3.8 \%$ of GDP in Australia [2]. Worldwide, the population is ageing, and demographics are changing as a result of decades of declining fertility rates and increasing longevity [3-6]. Social changes have resulted in the breaking of gender stereotypes and changing the role of family with more women in the workforce [3], smaller and dispersed families, lower marriage rates and higher divorce rates $[7,8]$. These changes also mean that we are facing an increasing burden of disease and disability with less people available to provide informal support and care. There are rising demands for carers in nursing homes and aged-care facilities, community disability services and for informal carers at home or outside [9]. Under such circumstances, like elsewhere in the world, formal care in Australia has not been able to cope with the required pace for the overall care need and informal carers have assumed a pivotal role in society.

Literature on informal carers' health has gathered momentum due to the impact of their caregiving on their overall health. The act of providing care by a carer is referred to as caregiving. Providing care for an elderly relative, spouse or a disabled child often restricts the life, social activities, and employment opportunities of the carer. Carers may have less time for leisure [10] or health promoting physical activity [10-12]. Recent evidence increasingly suggests that caregiving is a potential health risk and a chronic stressor that places carers at risk for physical and mental health problems [13-16]. Informal carers are suffering from worse health outcomes than the general population of their age and gender. Indeed, studies have found evidence of impaired health behaviours among carers helping with basic activities of daily living (ADLs) [17-20]. Carers tend to neglect their own health [18] and this impacts on their physical and mental health. Stronger impacts are observed on mental health than on physical health [18].

\section{Carer socioeconomic demographic characteristics and health} The effects on carer health are further exacerbated by the carer's age, socioeconomic status, and the availability of informal support [21]. Older carers, people of low socioeconomic status, and those with limited support networks report poorer psychological and physical health than carers who are younger and have more economic and interpersonal resources [21]. Studies have also shown that women carers have worse health outcomes than men [11, 22]. Studies which focused on specific groups, such as women carers in their 40 s and older age groups, and/or specific long-term health condition of the recipients, such as Alzheimer's disease or dementia, have found that the impact of caregiving on carer's health varies according to the relationship between the carer and the recipient. This gets further compounded by the gender of the carer. A recent longitudinal study among carers of Alzheimer's disease in Germany observed that providing care for spouse/ partner is more damaging for mental health of men and cognitive well-being of women compared to providing care for parents or parents-in-law [23]. Penning et al. (2015) in Canada found that, for women, caring for a spouse or children was more stressful and detrimental to mental health than caring for parents or others [24]. However, there is also evidence that gender differences in caregiving indicators were small to very small in magnitude [13]. A meta-analysis reveals that while women report higher levels of burden and depression, and lower levels of subjective well-being and physical health, they also provide more caregiving hours, help with more caregiving tasks, and assist with more personal care. Therefore, controlling for the gender differences in stressors and resources in statistical analyses reduces the size of gender differences in depression and physical health to levels that are observed in non-caregiving groups [13].

The magnitude of carers' suffering from adverse health outcomes depends on the number of hours they spent on caring duties and their level of workforce participation. Kenny et al. (2014) have identified that the combination of high levels of caregiving with full-time workforce participation increases the risk of negative physical and mental health outcomes particularly in female carers [22]. On the contrary, in Japan, the impact of high intensity caregiving on carers' mental health gets aggravated by non-workforce participation and the initial mental health status of the carer, while there is no impact observed on the serious mental distress of irregular employees [25]. Therefore, high intensity caregiving does not suit well either with full-time workforce participation or with non-workforce participation in influencing physical and mental health of carers. Farrugia et al. (2018) found as well that, in Australia, women carers reported worse mental health than non-carers while they were also, more likely to be working parttime or not be working at all [26]. Thus, there is a clear need for understanding the potentially modifying or protective effects of workforce participation on carer health. 
Studies suggest that social support realised through family and friends enhances health and wellbeing of people irrespective of their stress levels or protects people from the pathogenic effects of stressful events [27-30]. Consequently, it will be intriguing to assess if the carers' social support network exhibits any modifying or protective influence on their health.

\section{Carer health behaviour and health}

Although there is growing international literature on both the physical and mental health of carers, there is little focus on the possible pathways through which caregiving influences carer's health. Many reported studies are restricted in their scope and ability to understand the connection between caregiving and carer health in more detail. Vitaliano et al. (2003) identifies two pathways by which carer's chronic stress can impact their health [21]. One pathway could be that chronic stress leads to psychosocial distress and increases stress hormones that may contribute to disease development. The other pathway that leads to chronic stress may promote carer's unhealthy behaviours such as, drug and alcohol abuse, smoking, poor nutrition, and sedentary lifestyle, that are often associated with physical and mental health problems [20]. In an Australian study of women aged 50 years or more, carers reported higher symptoms of depression, anxiety and stress than non-carers [26]. This study also, reported significantly lower participation in health promoting activities and physical activities [26]. Consequently, there is a need to understand the link between caregiving, carer's healthy behaviour and health. Also, previous studies in Australia have not discussed in detail what might be the other contextual motivating factors that modify or protect carer's health.

\section{Rationale and study objectives}

Few studies have examined carers' health using a longitudinal analysis that follows an individual through their pre-to-post caregiving time. Carer's health status prior to the commencement of caregiving is an important confounder since pre-existing health disparities (beyond those accounted for by age and sex) between carers and non-carers might give rise to misleading conclusions in a cross-sectional analysis. A range of pre-existing factors such as poor socioeconomic status, disengagement with workforce, age, poor health, poor dietary or sedentary behaviour might predispose a person to become a carer $[21,22]$. An Australian study found that middle-aged women in poor health tend to be selected into caregiving roles, probably because they are less and/or not at all engaged with the paid workforce. Poor health and disengagement from the paid workforce continue even when caregiving stops [31]. Overall, the literature lacks evidence on understanding the association between a person's caregiving status (active carer/non-carer), health behaviour, other contextual factors and health in Australia using population-based longitudinal data. Filling this research gap would help in identifying risk and protective factors for carers' health, also in designing and implementing interventions that enhance protective factors and in reducing the impact of these risk factors on carers' health.

This study investigated the self-assessed mental and general health status of informal carers, compared to non-carers, in Australia using retrospective analysis of longitudinal survey data. Using this approach, we studied the health of individuals over time through their pre-topost caregiving years. Such longitudinal analysis inherently eliminated the effect of gender, personality traits and other individual level behavioural predispositions that did not change over time. In other words, a longitudinal fixed effects regression analysis controlled for the pre-existing health disparities in individuals and other factors such as their pre-existing poor socioeconomic status, disengagement with workforce, age, poor dietary or sedentary behaviour, that might have predisposed a person to become a carer. Additionally, we controlled for the effect of variation in age and socio-economic status on the health status of carers over time. The study focused on understanding the potentially modifying or protective effects of carer's workforce participation and the level of social engagement on their health.

The primary objectives of this study were to assess if caregiving status had an influence on overall health status and to understand whether carer's health behaviour, level of social engagement and employment status had modified impact on their health, controlling for the effect of other confounders in the model such as age and socio-economic status. Using a retrospective longitudinal study design and following the trajectory of an individual carer's life through their pre-to- post caregiving years, this study examined the influence of caregiving status and individual level health behaviours, such as alcohol use, smoking and physical activity level, employment status and level of social engagement, on their self-assessed mental and general health. It is anticipated that this may provide the foundation for designing intervention programs for carers to improve their health outcomes.

\section{Methods}

\section{Data source}

The data for this study came from the Household Income and Labour Dynamics of Australia (HILDA) survey. HILDA is a major largescale population based longitudinal survey of Australian households available over a period of 16 years [32]. The survey started in 2001 and follows the lives of more than 17,000 Australians each year. It collects information on economic and 
personal well-being, labour market dynamics, family life, household and family relationships, income and employment, health and education. Our analysis was restricted to the waves 5-15 (2005-15) spanning a period of 11 years. Our study sample contained Australians aged 15 years and over who completed the self-completion questionnaire (SCQ) that was introduced in HILDA in 2005 [32]. We used an unbalanced panel that included all respondents and enumerated persons who responded to the SCQ and were available at least in two waves (between wave 5 and 15) as opposed to a balanced panel that would only include information on individuals consistently responding in all waves. For more information on HILDA survey sampling methodology including their eligibility criteria, retention rate, missing data, weighting and clustering information please refer to the HILDA User Manual and HILDA project discussion paper series $\# 1 / 15$ [32, 33]. Our study sample consisted of 121,410 responses (or person-years of observation) of 23,251 individuals after excluding the missing values on key dependent and independent variables. On average individual responses were available across 5 waves with a maximum of 11 waves. Table 1 presents information on sample sizes, number of carers and their age across the waves.

\section{Measures}

The outcome variables included self-reported health, the scores on the Short Form 36 Questionnaire (SF-36), a widely used multi-dimensional measure of health-related quality of life, using data available in HILDA surveys. The SF-36 is a multi-purpose, short-form health survey that measures health across eight domains of physical and mental health, that is comprised of 36 questions that focus on general health, physical functioning, role physical, bodily pain, vitality, social functioning, mental health and role emotional [34]. We used general health, physical functioning and mental health domains as our outcome variables. Scores on each of the SF-36 domains are standardised and component scores range from 0 to 100. Higher scores indicated better health [34]. The SF36 is a generic measure, as opposed to one that targets a specific age, disease, or treatment group.

The SF-36 has proven useful in surveys of general and specific populations, comparing the relative burden of diseases, and have been translated in more than 50 countries as part of the International Quality of Life Assessment (IQOLA) Project; and studies of reliability and validity [35]. Studies of the SF-36 general health domain have yielded content, concurrent, criterion, construct, predictive evidence of validity and test-retest reliability with levels of internal consistence between 0.59-0.79, and estimates of reliability about 0.84 for the general health domain $[35,36]$.

We have included in our regression model a range of explanatory variables that were expected to have an influence on the general, physical or mental health of an individual over time along with his/her caregiving status. The caregiving status of the individual, the main factor of interest in this study, was defined in each wave as a dichotomous variable, where 1 represented the individuals who actively cared for a household member or nonresident individual due to a long-term health condition or elderly status (carers), and 0 represented those who were not active carers (non-carers). Carers specifically identified themselves as active carers in HILDA survey. We also included the number of hours a person spends on caregiving duties per week as a continuous variable irrespective of their caregiving status in each wave. Therefore, non-carers (or caregiving status $=0$ ) also reported the time they spent on some type of caregiving in the household over a week even if they had not identified themselves as active carers of someone needing long-term care in each wave. On average, non-carers spent much less time on caregiving duties than carers

Table 1 Sample size, Number of Carers and Carers' Age by Wave [5-15]

\begin{tabular}{|c|c|c|c|c|c|}
\hline Wave & Sample size & Number of Carers & Carer's Mean Age & Carer's Minimum Age & Carer's Maximum Age \\
\hline Wave 5 (2005) & 9843 & 670 & 49.9 & 15 & 89 \\
\hline Wave 6 (2006) & 9328 & 655 & 50.5 & 15 & 91 \\
\hline Wave 7 (2007) & 9076 & 566 & 51.4 & 15 & 90 \\
\hline Wave 8 (2008) & 8971 & 610 & 51.3 & 15 & 88 \\
\hline Wave 9 (2009) & 9200 & 593 & 51.6 & 15 & 89 \\
\hline Wave 10 (2010) & 9950 & 642 & 51.4 & 15 & 89 \\
\hline Wave 11 (2011) & 12,980 & 908 & 51.6 & 15 & 90 \\
\hline Wave 12 (2012) & 12,903 & 989 & 51.5 & 15 & 90 \\
\hline Wave 13 (2013) & 12,986 & 908 & 52.9 & 15 & 92 \\
\hline Wave 14 (2014) & 13,143 & 975 & 52.9 & 15 & 90 \\
\hline Wave 15 (2015) & 13,030 & 900 & 52.2 & 15 & 89 \\
\hline
\end{tabular}

Note: Table 1 presents sample size, number of carers and average age of carers in each wave of HILDA data 
(0.38 of an hour compared to $14.5 \mathrm{~h}$ a week). Table 2 presents the other time-dependent predictors (i.e. any predictor whose value for a given individual may have changed over time) such as sociodemographic variables, social network, smoking and drinking status, physical activity status, any major adverse health event occurred in the previous year and the weekly time (hours) spent on volunteering and charity work. Along with the daily/ weekly smoking status of an individual, we included the number of cigarettes a person usually smokes per week divided by 10 as an overall control variable. All these variables included in the model are fully detailed in the 2017 HILDA User Manual - Release 16 [32].

\section{Statistical methods}

We have fitted panel data fixed effects (FE) regression models $[37,38]$ to study the extent to which the informal caregiving status and caregiving time along with other time-varying independent variables were associated with the self-assessed general, physical and mental health status of individuals over a period of 11 years. A FE model was preferred over a random effects (RE) [39, 40] in this study primarily guided by our research objective. We examined the health impacts of caregiving for an individual by assessing change over time (controlling for pre-existing health status and socioeconomic status) from before caregiving to, in some cases, after caregiving responsibilities were over, that is, including transitions into and out of care-giving status. The FE modelling approach and our research objective were very well supported in this study using the HILDA survey data that exhibits enough longitudinal variation at individual level. Additionally, Hausman tests undertaken independently on the general and mental health component scores justified our preference of FE models over RE, the null hypothesis being that the preferred model is random effects (RE) while the alternative is the fixed effects (FE) $[41,42]$. Under the null hypothesis, the difference in estimated coefficients (RE vs. FE approaches) is not systematic. The test results in a chi-square statistic based on the difference in both coefficients and is expected to be small under the null hypothesis.

Increasing individuals' age was used as the changing time indicator in this analysis and the FE estimator was the weighted mean of the individuals' slopes. The model controlled for life events in the past year, time spent volunteering, time spent caregiving for disabled/elderly relatives, employment status, alcohol drinking combined with standard drinks per day (alcohol drinking status), physical activity status, social networking status, smoking status and number of cigarettes per week, as well as household gross total income, all included as fixed effects in the analysis. To test the moderation effects of the above-mentioned independent variables on outcomes, the models also included interaction-effects involving the interaction of carer's status with age, employment status, drinking status, physical activity, social networking and smoking status and tested whether such interaction effects were significant in predicting carers' health [43, 44].

We fitted separate models for each of the three SF-36 domain component scores. After estimating a series of regression equations on each health measure, we had selected and presented the model that best fits our sample data and answers the research question. Standard errors for clustered errors at the individual level were computed to account for heteroscedasticity and serial correlation of the error terms [45]. Analyses were performed using STATA 14 (XTREG FE) with robust standard errors estimation $[46,47]$.

\section{Results}

The descriptive statistics of the total responses (i.e. 121, 410 observation-years) along with the minimum and maximum average values across 11 waves are presented in Table 2. The average age across all respondents' observation-years was 44 years. Carers' age ranged from 15 to 92 years with an average age of 52 years across all waves. The number of carers varied from 566 (wave 7) to 989 (wave 12) (see Table 1), and they constituted nearly $7 \%$ of the total observation-years. Those who served as carers, on an average spent 2.7 years on active caregiving responsibilities over the 11 year window. While in active caregiving status, people spent on average 14.5 (Standard Deviation $(\mathrm{SD})=26.8$ ) hours a week in caregiving activities, compared to non-carers who spent less than an hour ( 0.38 of an hour with a $\mathrm{SD}=$ 3.6). In total, $42.5 \%$ of the respondents were in full-time employment. The alcohol and smoking status revealed $18 \%$ of the respondents across all waves were nondrinkers and $81 \%$ were non-smokers.

\section{Carer and non-carer health}

Figures 1 and 2 present mean values of carer and noncarer's health status across the waves by gender. Overall, non-carers showed better outcomes than carers in all three health measures. Also, non-carers showed consistently even and slightly declining trends over time with males doing better than females in mental health and physical functioning. Whereas carers showed fluctuating and slightly decreasing trends over the years in all three health measures with the exception of mental health for males, where we see a slightly increasing trend over the years.

Results of the fully adjusted FE models are presented in Table 3 for both SF36 mental (first three columns) and general health (subsequent three columns). In Table 3, the first row presents the impact of Carer Status on mental health and general health outcomes. The following section titled Effects on Non-Carer Status: main terms, presents 
Table 2 Descriptive Statistics of the Variables over time (Waves 5-15)

\begin{tabular}{|c|c|c|c|}
\hline Variable & $\begin{array}{l}\text { Mean/Percent } \\
\text { (total responses }=121,410, \mathrm{~N}=23,251 \text { ) }\end{array}$ & $\begin{array}{l}\text { Minimum Average } \\
\text { across waves }\end{array}$ & $\begin{array}{l}\text { Maximum Average } \\
\text { across waves }\end{array}$ \\
\hline SF36 Mental Health Component Score & $74.41(17.08)$ & 73.61 & 74.99 \\
\hline SF36 General Health Component Score & $68.46(20.94)$ & 67.25 & 69.69 \\
\hline SF36 Physical Functioning Component Score & $83.90(22.92)$ & 83.43 & 84.60 \\
\hline Household financial year gross total income (\$) & $108,261.2(102,164.1)$ & $81,929.9$ & $126,464.0$ \\
\hline Age & $44.17(18.54)$ & 43.4 & 44.9 \\
\hline $\begin{array}{l}\text { Life events in past year: Serious personal injury/illness (\# of } \\
\text { events) }\end{array}$ & 8.79 & 7.59 & 9.75 \\
\hline Time spent (hrs/mins) per week Volunteer/Charity work & $0.99(3.48)$ & 0.9 & 1.1 \\
\hline \multicolumn{4}{|l|}{ Employment Status } \\
\hline Employed - works 35 hours a week (Base Category) & 42.46 & 40.82 & 44.34 \\
\hline Employed - works less than 35 hours a week & 20.78 & 20.33 & 21.36 \\
\hline Unemployed, retired, home duties, students \& others & 36.76 & 34.99 & 38.20 \\
\hline Carer Characteristics & & 40.82 & 44.34 \\
\hline $\begin{array}{l}\text { Actively cares for a household member/non-resident due to } \\
\text { long-term health condition, elderly (\%) }\end{array}$ & 6.93 & 6.24 & 7.66 \\
\hline $\begin{array}{l}\text { Time spent in (hrs/mins) per week Caring for disabled/elderly } \\
\text { relative }(n=8416)\end{array}$ & $14.55(26.85)$ & 11.47 & 17.52 \\
\hline Carers' Age $(n=8416)$ & $51.65(15.89)$ & 49.91 & 52.86 \\
\hline \multicolumn{4}{|l|}{ Alcohol drinking status } \\
\hline Never drink/No longer drink (Base category) & 18.12 & 16.17 & 20.16 \\
\hline Drink only rarely & 22.82 & 21.92 & 23.53 \\
\hline Drink $2 / 3$ days per month & 12.61 & 11.40 & 13.35 \\
\hline Drink $1 / 2$ days per week & 18.91 & 18.12 & 19.52 \\
\hline Drink 3 or more days per week & 27.54 & 25.13 & 30.65 \\
\hline \multicolumn{4}{|l|}{ Standard drinks per day } \\
\hline Don't drink (Base Category) & 18.12 & 16.17 & 20.16 \\
\hline 1 to 2 standard drinks & 42.82 & 41.92 & 44.67 \\
\hline 3 to 4 standard drinks & 21.24 & 20.50 & 22.08 \\
\hline 5 and more standard drinks & 17.82 & 16.96 & 19.20 \\
\hline \multicolumn{4}{|l|}{ How often participate in Physical Activities? } \\
\hline Not at all (Base Category) & 10.52 & 9.17 & 11.18 \\
\hline Less than once a week & 15.81 & 14.65 & 17.18 \\
\hline 1 to 2 times a week & 23.66 & 22.72 & 24.41 \\
\hline 3 times a week & 16.07 & 15.59 & 16.79 \\
\hline More than 3 times a week & 33.94 & 33.09 & 35.39 \\
\hline \multicolumn{4}{|l|}{ How often get together socially with friends/relatives? } \\
\hline Every Day & 3.91 & 3.08 & 4.73 \\
\hline Several times a week & 23.65 & 21.92 & 26.37 \\
\hline About once a week & 31.61 & 30.99 & 32.60 \\
\hline 1 to 3 times a month & 29.89 & 28.02 & 32.07 \\
\hline 1 or 2 times every 3 months & 5.78 & 4.64 & 6.46 \\
\hline Less often than once every 3 months (Base Category) & 5.17 & 4.30 & 5.70 \\
\hline \multicolumn{4}{|l|}{ Smoking Status } \\
\hline Never smoked/No longer smoke (Base Category) & 81.39 & 77.65 & 83.59 \\
\hline
\end{tabular}


Table 2 Descriptive Statistics of the Variables over time (Waves 5-15) (Continued)

\begin{tabular}{llll}
\hline Variable & $\begin{array}{l}\text { Mean/Percent } \\
\text { (total responses =121,410, N =23,251) }\end{array}$ & $\begin{array}{l}\text { Minimum Average } \\
\text { across waves }\end{array}$ & $\begin{array}{l}\text { Maximum Average } \\
\text { across waves }\end{array}$ \\
\hline Smoke less often than weekly & 1.53 & 1.36 & 1.82 \\
Smoke at least weekly (but not daily) & 1.80 & 1.53 & 2.26 \\
Smoke daily & 15.28 & 13.34 & 18.28 \\
Number of cigarettes usually smoked each week & 14.95 & 12.9 & 17.2 \\
& $(42.47)$ & \\
\hline
\end{tabular}

Note: The Table 2 presents summary statics of the variables used in the fully-adjusted fixed effects models for the SF36 mental and general health outcomes across 11 waves (wave 5-15) of HILDA data

the estimates of effects of non-carer's characteristics such as their age and caregiving time and their health behaviours (physical activity level, smoking and drinking level), employment status and level of social engagement. The section titled Differences in Carer versus Non-carer Status: interaction terms, presents the non-carer and carer status differential estimated effects. Overall the caregiving status was interacted with other individual characteristics (such as their age and caregiving time, health behaviours, employment status and level of social engagement) to produce Carer differential effects. There were statistically significant carer/non-carer status differences in mental health (estimate (Beta) $=-0.587,95 \%$ confidence interval (CI): $(-0.972,-0.203), p=0.003)$ and general health $($ Beta $=-0.670,95 \%$ CI: $(-1.058,-0.283), p=0.001)$. On the other hand, there was no significant carer-noncarer status difference in SF-36 physical functioning scores (as shown in Table 4). Consequently, we did not proceed with further analyses for this component. Individuals showed significant disadvantages in both mental and general health outcomes due to being active carers across waves. These carer status disadvantages remained highly statistically significant even after controlling for a range of other household and personal level social, economic, demographic characteristics, smoking, drinking and health behaviour in the model (Table 3). On average, carers reported worse mental and general health scores that are 3 points less than those of non-carers. Additionally, we found that the time spent per week in caregiving duties was negatively related to the mental health score but not to the general health score. The negative influence of time spent on caregiving duties was persistent across carer status levels even though on average people in non-carer's status spent much less time on caregiving than those in carer's status ( 0.38 of an hour compared to $14.5 \mathrm{~h}$ a week). Other confounders in the model, namely, household gross income, any serious personal injury/illness in the past year and time spent per week volunteering/charity work had impact on both mental and general health measures in the expected direction in the overall model. The first two of these expected effects were statistically significant, whereas time spent in volunteering/charity work was not significant.

\section{Aging and Carer health}

The carer health trends over time revealed interesting patterns in this study. There was a clear pattern of

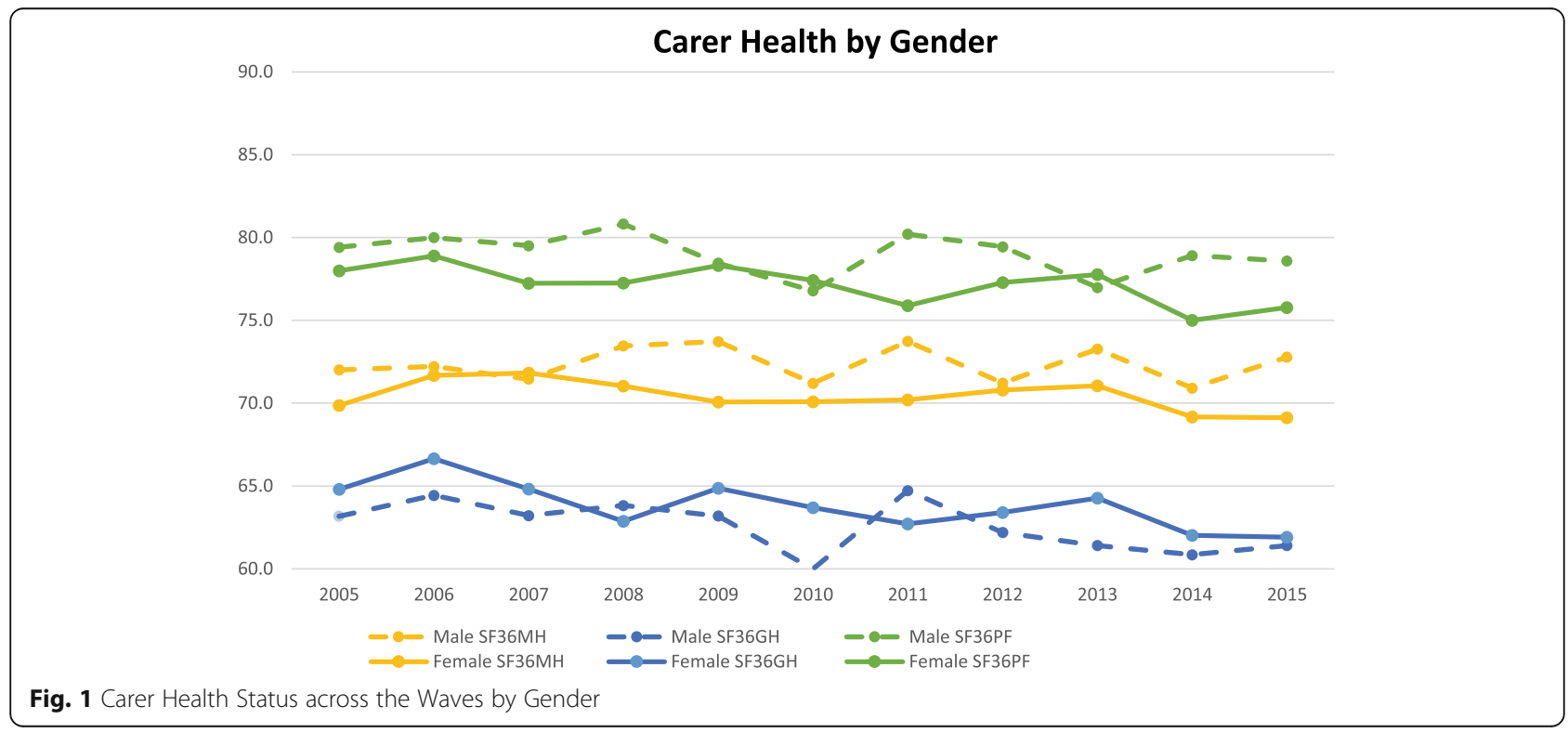




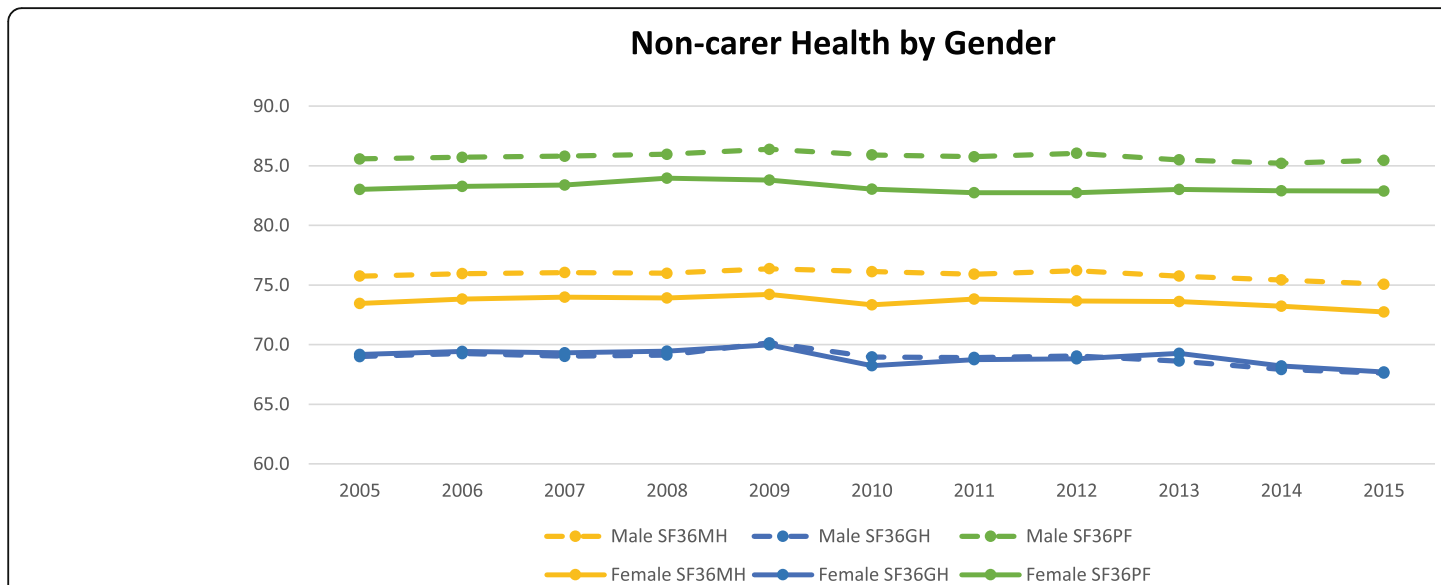

Fig. 2 Non-carer Health Status across the Waves by Gender

decreasing mental and general health status for both carers and non-carers with their age. Figures 3 and 4 present mental and general health marginal mean trends respectively (adjusted predictions) over time (with age as time) for carer and non-carer groups. Both mental and general health scores decreased significantly with age, but at different rates for carers and non-carers. In unadjusted models for mental health, estimates of rates of change were: Beta $=-0.054$ (95\% CI: $(-0.084,-0.024), p<0.001)$ for non-carers; Beta $=-0.034$ (95\% CI: $(-0.071,0.004)$, $p=0.077)$ for carers, and the difference in rates of change was not statistically significant $(p=0.088)$. For general health, estimates were: Beta $=-0.477$ (95\% CI: $(-0.509,-$ $0.443), \mathrm{p}<0.001)$; Beta $=-0.437$ (95\% CI: $(-0.477,-$ $0.397), \mathrm{p}<0.001)$, for non-carers and carers respectively, and the difference in slopes was significant $(p=0.002)$. As shown in Figs. 3 and 4, carer status modified the effect of aging on mental and general health with a slower rate of decline for carers compared to non-carers (moderation effect). The decreasing pattern in mental and general health with aging remained for non-carer status, in fully adjusted models as shown in Table 3. However, the adjusted decrease was non-significant for mental health, but significant for general health. The difference in rates of change due to carer status was on the margin of statistical significance for mental health at the $10 \%$ level, but remained significant for general health at $5 \%$ level.

\section{Health behaviour and Carer health}

Interactions of individuals' health behaviours, such as their drinking and smoking status and physical activity level, with their carer/non-carer status, revealed quite intriguing relations with both mental and general health scores.

Results for alcohol drinking status when interacted with the number of standard drinks consumed per day revealed that in non-carers, any level of drinking, compared to those who did not drink, had a negative effect on mental health score with increasing patterns. However, the drinking status exhibited quite an intriguing pattern in terms of its effect on non-carers' general health score (Table $3,4^{\text {th }}$ column). For example, if a person was a social drinker and drank only 2-3 days per month with only 1 to 2 standard drinks or even 1-2 days per week with 1 to 2 standard drinks then that had a positive effect on general health score compared to those who did not drink. On the other hand, if a person drank 5 or more standard drinks for only 2 to 3 days per month or drank on a weekly basis then that had a negative effect on general health score. In the case of carer status, the effect modification was significant for mental health only in light drinkers ("drink only rarely", or "drink 2-3 days per month") who consumed 3 to 4 standard drinks with on average a 2-points higher score. The same effect modification was apparent for general health in the same groups as for mental health. However, the 2-points difference on average (in favour of carers) was only marginally significant at the $10 \%$ level.

As expected for smoking status, results revealed that, in non-carers, smoking daily had a significant negative effect on mental health score, whereas any level of smoking had a negative effect on general health score, increasing with the level of smoking status. For those in carer status, light (smoke less often than weekly) and medium (smoke at least weekly, but not daily) smoking was more detrimental to mental health than was smoking daily. This was not the case for general health, where the negative effect of smoking got stronger as the levels of smoking increased. Overall, we have also controlled for the number of cigarettes a person usually smokes per week and found a statistically significant negative effect on the persons' general health (irrespective of carer/noncarer status).

As for physical activity status, when someone was a non-carer, any level of exercising, compared to those 
Table 3 Fully adjusted fixed effects models separately for the SF36 Mental and General Health components: Estimates of carer status effect, effects of individual characteristics on non-carer status and carer status differential effects (interaction effects)

\begin{tabular}{|c|c|c|c|c|c|c|}
\hline \multirow{3}{*}{$\begin{array}{l}\text { Variables } \\
\text { Carer Status (Yes/No): Actively cares for a household member/non-resident due to long- } \\
\text { term health condition, elderly }\end{array}$} & \multicolumn{3}{|c|}{$\begin{array}{l}\text { SF36 Mental } \\
\text { Health Component }\end{array}$} & \multicolumn{3}{|c|}{$\begin{array}{l}\text { SF36 General } \\
\text { Health Component }\end{array}$} \\
\hline & \multirow{2}{*}{$\begin{array}{l}\text { Coef. } \\
-3.010^{* * *}\end{array}$} & \multicolumn{2}{|c|}{$\begin{array}{l}\text { [95\% Conf. } \\
\text { Interval] }\end{array}$} & \multirow{2}{*}{$\begin{array}{l}\text { Coef. } \\
-3.106^{* * *}\end{array}$} & \multicolumn{2}{|c|}{$\begin{array}{l}\text { [95\% Conf. } \\
\text { Interval] }\end{array}$} \\
\hline & & -5.371 & -0.648 & & -5.378 & -0.83 \\
\hline \multicolumn{7}{|l|}{ Effects on Non-Carer Status: main terms } \\
\hline Non-Carer: Age & -0.009 & -0.039 & 0.021 & $-0.421^{* * *}$ & -0.453 & -0.390 \\
\hline Non-Carer: Time spent in (hrs/mins) per week Caring for disabled/elderly relative & $-0.039^{* * *}$ & -0.065 & -0.012 & -0.003 & -0.025 & 0.018 \\
\hline \multicolumn{7}{|l|}{ Non-Carer: Employment Status } \\
\hline \multicolumn{7}{|l|}{ Employed - works 35 hours a week (Reference group) } \\
\hline Employed - works less than 35 hours a week & $-0.560^{* * *}$ & -0.838 & -0.282 & $-0.706^{* * *}$ & -0.985 & -0.427 \\
\hline Unemployed, retired, home duties, students \& others & $-1.412^{* * *}$ & -1.746 & -1.077 & $-1.158^{* * *}$ & -1.498 & -0.817 \\
\hline \multicolumn{7}{|l|}{ Non-Carer: Alcohol Drinking Status } \\
\hline \multicolumn{7}{|l|}{ Never drink/No longer drink (Reference group) } \\
\hline Drink only rarely \& 1 to 2 standard drinks & $-0.414^{* *}$ & -0.813 & -0.014 & 0.259 & -0.129 & 0.647 \\
\hline Drink only rarely \& 3 to 4 standard drinks & $-0.818^{* * *}$ & -1.385 & -0.250 & -0.195 & -0.744 & 0.353 \\
\hline Drink only rarely \& 5 and more standard drinks & $-1.289^{* * *}$ & -2.020 & -0.558 & -0.208 & -0.915 & 0.499 \\
\hline Drink $2 / 3$ days per month \& 1 to 2 standard drinks & -0.416 & -0.906 & 0.074 & $0.502^{* *}$ & 0.015 & 0.990 \\
\hline Drink $2 / 3$ days per month $\& 3$ to 4 standard drinks & $-0.806^{* * *}$ & -1.352 & -0.259 & 0.027 & -0.541 & 0.595 \\
\hline Drink $2 / 3$ days per month \& 5 and more standard drinks & $-1.912^{* * *}$ & -2.526 & -1.299 & -0.501 & -1.112 & 0.110 \\
\hline Drink $1 / 2$ days per week \& 1 to 2 standard drinks & $-0.726^{* * *}$ & -1.212 & -0.240 & $0.479^{*}$ & -0.011 & 0.969 \\
\hline Drink $1 / 2$ days per week \& 3 to 4 standard drinks & $-1.308^{* * *}$ & -1.847 & -0.768 & 0.048 & -0.492 & 0.589 \\
\hline Drink $1 / 2$ days per week $\& 5$ and more standard drinks & $-1.735^{* * *}$ & -2.313 & -1.157 & $-0.806^{* * *}$ & -1.381 & -0.231 \\
\hline Drink 3 or more days per week \& 1 to 2 standard drinks & $-0.962^{* * *}$ & -1.489 & -0.435 & 0.301 & -0.236 & 0.839 \\
\hline Drink 3 or more days per week \& 3 to 4 standard drinks & $-1.896^{* * *}$ & -2.460 & -1.332 & -0.292 & -0.863 & 0.279 \\
\hline Drink 3 or more days per week \& 5 and more standard drinks & $-2.998^{* * *}$ & -3.664 & -2.332 & $-1.342^{* * *}$ & -1.995 & -0.689 \\
\hline \multicolumn{7}{|l|}{ Non-Carer: How often participate in Physical Activities? } \\
\hline \multicolumn{7}{|l|}{ Not at all (Reference group) } \\
\hline Less than once a week & $1.304^{* * *}$ & 0.942 & 1.665 & $2.219^{* * *}$ & 1.847 & 2.591 \\
\hline 1 to 2 times a week & $2.412^{* * *}$ & 2.042 & 2.781 & $4.118^{* * *}$ & 3.733 & 4.502 \\
\hline 3 times a week & $3.394^{* * *}$ & 2.996 & 3.791 & $5.679^{* * *}$ & 5.271 & 6.087 \\
\hline More than 3 times a week & $4.528^{* * *}$ & 4.131 & 4.926 & $7.628^{* * *}$ & 7.210 & 8.045 \\
\hline \multicolumn{7}{|l|}{ Non-Carer: How often get together socially with friends/relatives? } \\
\hline Every Day & $4.984^{* * *}$ & 4.297 & 5.670 & $3.008^{* * *}$ & 2.361 & 3.656 \\
\hline Several times a week & $4.483^{* * *}$ & 3.947 & 5.018 & $2.695^{* * *}$ & 2.203 & 3.186 \\
\hline About once a week & $3.434^{* * *}$ & 2.920 & 3.947 & $2.115^{* * *}$ & 1.648 & 2.582 \\
\hline 1 to 3 times a month & $2.536^{* * *}$ & 2.041 & 3.032 & $1.588^{* * *}$ & 1.136 & 2.041 \\
\hline 1 or 2 times every 3 months & $1.155^{* * *}$ & 0.607 & 1.703 & $0.501^{* *}$ & 0.000 & 1.002 \\
\hline
\end{tabular}

Less often than once every 3 months (Reference group)

Non-Carer: Smoking Status

[Never smoked/No longer smoke (Reference group)

Smoke less often than weekly

$\begin{array}{llllll}0.053 & -0.710 & 0.816 & -0.836^{* *} & -1.597 & -0.076\end{array}$

Smoke at least weekly (but not daily)

$\begin{array}{llllll}-0.433 & -1.175 & 0.309 & -1.175^{* * *} & -1.891 & -0.460\end{array}$

Smoke daily

$-0.746^{* *}-1.360-0.133-1.231^{* * *}-1.838-0.625$ 
Table 3 Fully adjusted fixed effects models separately for the SF36 Mental and General Health components: Estimates of carer status effect, effects of individual characteristics on non-carer status and carer status differential effects (interaction effects) (Continued)

\begin{tabular}{|c|c|c|c|c|c|c|}
\hline \multirow[t]{2}{*}{ Variables } & \multicolumn{3}{|c|}{$\begin{array}{l}\text { SF36 Mental } \\
\text { Health Component }\end{array}$} & \multicolumn{3}{|c|}{$\begin{array}{l}\text { SF36 General } \\
\text { Health Component }\end{array}$} \\
\hline & Coef. & \multicolumn{2}{|c|}{$\begin{array}{l}\text { [95\% Conf. } \\
\text { Interval] }\end{array}$} & Coef. & \multicolumn{2}{|c|}{$\begin{array}{l}\text { [95\% Conf. } \\
\text { Interval] }\end{array}$} \\
\hline \multicolumn{7}{|l|}{ Differences in Carer versus Non-carer Status: interaction terms } \\
\hline Carer \& Age & $0.024^{*}$ & -0.004 & 0.051 & $0.034^{* *}$ & 0.006 & 0.062 \\
\hline Carer \& Time spent in (hrs/mins) per week Caring for disabled/elderly relative & 0.021 & -0.008 & 0.050 & 0.012 & -0.013 & 0.036 \\
\hline \multicolumn{7}{|l|}{ Carer \& Employment Status } \\
\hline \multicolumn{7}{|l|}{ Employed - works 35h hours a week (Reference group) } \\
\hline Employed - works less than $35 \mathrm{~h}$ a week & 0.100 & -0.835 & 1.036 & -0.312 & -1.195 & 0.571 \\
\hline Unemployed, retired, home duties, students \& others & 0.057 & -0.846 & 0.961 & -0.291 & -1.184 & 0.602 \\
\hline \multicolumn{7}{|l|}{ Carer \& Alcohol drinking status } \\
\hline \multicolumn{7}{|l|}{ Never drink/No longer drink (Reference group) } \\
\hline Drink only rarely \& 1 to 2 standard drinks & 0.279 & -0.791 & 1.349 & 0.717 & -0.331 & 1.766 \\
\hline Drink only rarely \& 3 to 4 standard drinks & $2.165^{* *}$ & 0.234 & 4.096 & $1.922^{*}$ & -0.132 & 3.977 \\
\hline Drink only rarely \& 5 and more standard drinks & -0.577 & -3.043 & 1.890 & -0.338 & -2.866 & 2.190 \\
\hline Drink $2 / 3$ days per month $\& 1$ to 2 standard drinks & -0.135 & -1.603 & 1.334 & 0.020 & -1.461 & 1.500 \\
\hline Drink $2 / 3$ days per month \& 3 to 4 standard drinks & $2.389^{* *}$ & 0.435 & 4.342 & $2.073^{*}$ & -0.032 & 4.178 \\
\hline Drink $2 / 3$ days per month $\& 5$ and more standard drinks & -0.299 & -2.747 & 2.149 & 0.465 & -1.699 & 2.630 \\
\hline Drink $1 / 2$ days per week \& 1 to 2 standard drinks & 0.462 & -0.857 & 1.783 & -0.222 & -1.545 & 1.101 \\
\hline Drink $1 / 2$ days per week \& 3 to 4 standard drinks & 1.028 & -0.778 & 2.835 & -0.375 & -2.101 & 1.350 \\
\hline Drink $1 / 2$ days per week \& 5 and more standard drinks & -1.144 & -3.222 & 0.935 & 0.679 & -1.612 & 2.970 \\
\hline Drink 3 or more days per week \& 1 to 2 standard drinks & -0.237 & -1.401 & 0.926 & 0.347 & -0.847 & 1.540 \\
\hline Drink 3 or more days per week \& 3 to 4 standard drinks & 0.340 & -1.065 & 1.746 & 1.091 & -0.273 & 2.455 \\
\hline Drink 3 or more days per week \& 5 and more standard drinks & 0.653 & -1.168 & 2.475 & 0.958 & -0.716 & 2.632 \\
\hline
\end{tabular}

Carer \& How often participate in Physical Activities?

Not at all (Reference group)

Less than once a week

1 to 2 times a week

3 times a week

More than 3 times a week

Carer \& How often get together socially with friends/relatives?

Every Day

Several times a week

About once a week

1 to 3 times a month

1 or 2 times every 3 months

Less often than once every 3 months (Reference group)

Carer \& Smoking Status

Never smoked/No longer smoke (Reference group)

Smoke less often than weekly

Smoke at least weekly (but not daily)

Smoke daily

Other Overall Control Variables: effect for the whole sample

Standardized Household financial year gross total income (\$)
0.41

$\begin{array}{llllll}0.419 & -0.766 & 1.605 & -0.085 & -1.182 & 1.012 \\ 1.050^{*} & -0.092 & 2.191 & 0.502 & -0.584 & 1.589 \\ 1.273^{* *} & 0.069 & 2.477 & 0.346 & -0.817 & 1.509 \\ 1.005^{*} & -0.137 & 2.147 & 0.073 & -1.037 & 1.182 \\ & & & & & \\ -1.529 & -3.812 & 0.753 & -1.016 & -3.363 & 1.332 \\ 0.498 & -1.032 & 2.027 & 0.633 & -0.774 & 2.041 \\ -0.009 & -1.480 & 1.462 & 0.289 & -1.066 & 1.644 \\ 0.110 & -1.312 & 1.532 & 0.453 & -0.877 & 1.782 \\ 1.176 & -0.500 & 2.853 & 0.633 & -0.932 & 2.199\end{array}$

$\begin{array}{llllll}-1.820 & -4.439 & 0.799 & 0.525 & -2.155 & 3.204 \\ -1.348 & -4.176 & 1.480 & 0.056 & -2.913 & 3.025 \\ 0.660 & -0.522 & 1.843 & -0.382 & -1.466 & 0.702 \\ & & & & & \\ 0.195^{* * *} & 0.091 & 0.298 & 0.129^{* * *} & 0.031 & 0.227\end{array}$


Table 3 Fully adjusted fixed effects models separately for the SF36 Mental and General Health components: Estimates of carer status effect, effects of individual characteristics on non-carer status and carer status differential effects (interaction effects) (Continued)

\begin{tabular}{|c|c|c|c|c|c|c|}
\hline \multirow[t]{2}{*}{ Variables } & \multicolumn{3}{|c|}{$\begin{array}{l}\text { SF36 Mental } \\
\text { Health Component }\end{array}$} & \multicolumn{3}{|c|}{$\begin{array}{l}\text { SF36 General } \\
\text { Health Component }\end{array}$} \\
\hline & Coef. & $\begin{array}{l}\text { [95\% Cc } \\
\text { Interval] }\end{array}$ & & Coef. & $\begin{array}{l}\text { [95\% Cc } \\
\text { Interval] }\end{array}$ & \\
\hline Life events in past year: Serious personal injury/illness & $-3.713^{* * *}$ & -4.025 & -3.401 & $-6.182^{* * *}$ & -6.518 & -5.846 \\
\hline Time spent (hrs/mins) per week Volunteer/Charity work & $0.026^{*}$ & -0.002 & 0.054 & 0.017 & -0.015 & 0.049 \\
\hline Number of cigarettes usually smoked each week/10 & -0.037 & -0.085 & 0.011 & $-0.050 * *$ & -0.096 & -0.005 \\
\hline
\end{tabular}

Notes. All the $p$-values have been replaced by stars and categorised as follows. ${ }^{* *}: p<0.01 ;{ }^{* *}: p<0.05 ; *: p<0.1$; However, confidence intervals use the usual $95 \%$ confidence level. The first row presents the impact of Carer Status on SF36 mental health and general health outcomes of individuals over time. The following section titled Effects on Non-Carer Status: main terms, presents the estimates of individual characteristics such as their age and caregiving time and the impact of their health behaviours (physical activity level, smoking and drinking level), employment status and level of social engagement on their self-assessed health status when they were non-carers. The next section titled Differences in Carer versus Non-carer Status: interaction terms, presents the non-carer and carer status differential estimates (the carer status has been interacted with other characteristics to estimate the magnitude of these differentials). Therefore, for each variable with both main and interaction terms in the model, the effect associated with carer status is given by the sum of both the non-carer status effect and the differential effects. The last section titled Other Overall Control Variables: effect for the whole sample presents the effects of characteristics associated to the whole sample (effects assumed to be the same in both non-care and carer groups)

who did not undertake any activity, had a positive and increasing influence on both mental and general health scores, with more activities generating better health outcomes. Carer/non-carer status differences in effects appeared to be all positive for mental health, meaning that physical activities were even more beneficial when someone served as a carer, though the benefit was significant only at the physical activity level of 3 times per week.

\section{Social engagement, employment and Carer health}

Overall, the level of social engagement and employment status when serving as a carer did not show any significant carer and non-carer status differential effect on health. However, results on employment status revealed that a non-carer and full-time employed person reported both better mental and general health scores compared to part-time employees, pensioners, students and housewives. But, employment status had no significant modifying effect on mental and general health scores when someone served as a carer.

Similarly, for social interactions and communication with friends and relatives, when non-carer, the more often a person got together with friends/relatives, compared to infrequent interactions (less often than once in 3 months), the better mental and general health status they enjoyed. However, results showed no significant carer/non-carer status differences.

\section{Discussion}

This paper presents a large population-based retrospective study of individual level mental and general health of Australians in relation to their informal caregiving status using a longitudinal analysis. The study added substantial value to the literature on carer's health by conducting a general population-based analysis that follows the individual person over their pre-to-post caregiving years. The study supported the evidence that being an active carer for a household member/non-resident due to long-term health condition and/or elderly status had a negative impact on both mental and general health of the carer. The time spent in care giving had a negative effect on mental health even for non-active carers when they only spent a few hours on caregiving tasks per week. Further, the study identified modifying effects of some of the risk and protective factors for carer health in Australia.

Table 4 Estimates of the Fixed Effects Base Model for SF36 Physical Functioning Component

\begin{tabular}{|c|c|c|c|}
\hline \multirow[t]{2}{*}{ Variables } & \multicolumn{3}{|c|}{ SF36 Physical Functioning Component } \\
\hline & Coef. (Standard Error) & $\begin{array}{l}{[95 \% \text { Conf. }} \\
\text { Coef. }\end{array}$ & \\
\hline $\begin{array}{l}\text { Carer Status (Yes/No): Actively cares for a household } \\
\text { member/non-resident due to long-term health condition, elderly }\end{array}$ & $-0.199(0.240)$ & -0.669 & 0.271 \\
\hline Constant & $83.913^{* * *}(.017)$ & 83.880 & 83.946 \\
\hline sigma_u & \multicolumn{3}{|l|}{21.537} \\
\hline sigma_e & \multicolumn{3}{|l|}{13.109} \\
\hline rho & \multicolumn{3}{|c|}{0.730 (fraction of variance due to $u_{i}$ i) } \\
\hline
\end{tabular}

Notes. All the $p$-values have been replaced by stars and categorised as follows. ${ }^{* *}: p<0.01 ;{ }^{* *}: p<0.05 ;{ }^{*}: p<0.1$; However, confidence intervals use the usual 95\% confidence level; sigma_u: Within-individuals variance; sigma_e: Residual variance; rho: Percentage of total variance due to within-individuals variation (or ICC, the intra-class correlation, measure of intra-individual correlation) 


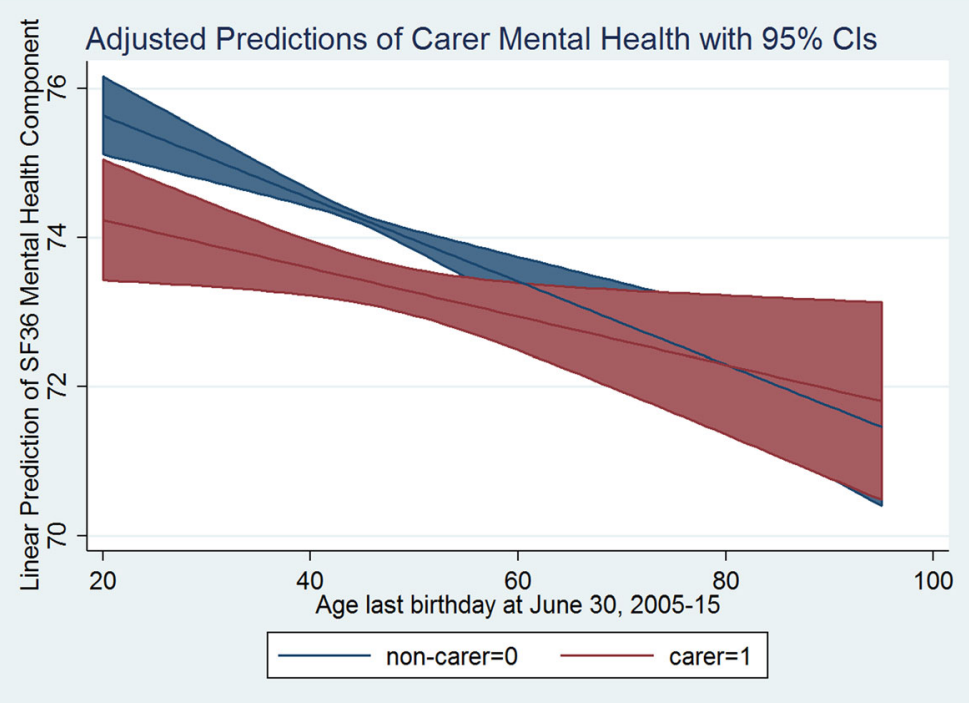

Fig. 3 Adjusted Predictions of Carer Mental Health with 95\% Cls

\section{Aging and Carer health}

The aging of an individual is associated with worsening physical and/or mental health status in the literature $[4,48]$. Mental health may in turn be influenced by the reduction in physical health (or vice versa) and loss of physical functioning due to aging and associated disability that renders a person less mobile. This effect was evidenced in this study with a significant negative effect of age on general health score when someone was a non-carer and a negative (but nonsignificant) effect on mental health. On the contrary, general population level epidemiological research suggests that the prevalence of mental illness decreases considerably with increasing age. There is an understanding that the prevalence of mental distress is highest in the 25-34 age group and decreases with increasing age [49]. Nevertheless, this study investigated the influence of caregiving status on an individual's health over their life (following the individual over time) and led to the observation of a protective effect of age on carer's health. In doing so, as documented earlier in this paper, the individual person's initial health status was an important confounder in the analysis. Consequently, adjusted predictions with age in Figs. 3 and 4 supported the

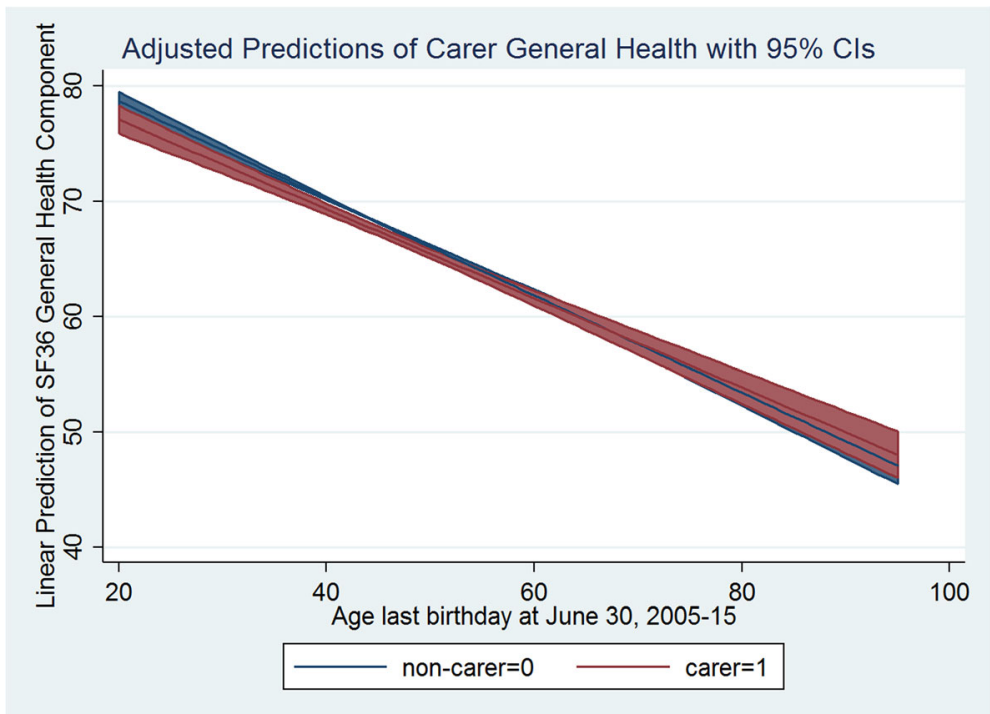

Fig. 4 Adjusted Predictions of Carer General Health with 95\% Cls 
evidence that, at the individual level for non-carers, irrespective of their initial (general/mental) health status, both general and mental health deteriorated with age. More importantly, the study found a positive impact of caregiving status through the attenuation of the carer's age effect on both mental and general health. This is an important finding that has significant policy implication. In case of carers, increasing age is associated with less decline in health. With age, carers report better mental and general health than non-carers. In other words, carer and non-carer differences in health may be less pronounced in older age than in younger age. It may also be the case that after certain age, older carers exhibit even better health outcomes than non-carers of the same age. This finding may help policy makers to design interventions to support young carers. Young informal carers may find themselves prematurely burdened with the unprecedented caregiving needs of their loved ones. In substantiating our findings, some recent Australian studies have recognised that the young informal carers are indeed at disadvantage compared to carers in older age groups. They face reduced opportunities to access education and employment, or to participate in social and community activities and consequently may also be experiencing financial hardship [50-53]. An important policy initiative to improve their circumstances, may be to provide better income support that could allow them additional time and resources needed. Community programs involving interactive social and physical activities could help young carers to cope better with their caregiving burden. Additionally, respite care programs may be more productive if focused on young carers [49]. Most informal carers in Australia, however, are in the working age group (25-64 years) and the average carers' age across waves in our sample is 52 years. Carers in this age group, while facing similar difficulties and benefits as carers in other age groups in terms of reduced participation in the labour force, increased unemployment and reduced earnings, they also face the extra burden of needing and/or wanting to work, or to remain in education or training, while providing care to others [50,51]. On the other hand, in Australia evidence supports that older carers' circumstances are somehow better than others. They are likely to be more experienced as carers, their income and social support network are less likely to be affected by their caregiving responsibilities, while they also tend to rather enjoy their caregiving role $[50,51]$. Therefore, the positive attenuation effect of age on carer general and mental health in this paper is rather a robust finding that should be supported with appropriate policy and used for designing age-specific interventions.

\section{Health behaviour and Carer health}

Consistent with existing literature on the positive relationship between physical activity and cardio-metabolic health [54-57], this study found that physical activity had a positive and significant influence on mental and general health when someone was a non-carer. More importantly, physical activities also had an additional modifying effect on mental health when someone was a carer. Based on previous research, while carers may predispose themselves into sedentary behaviour [58], this study found that, while serving as a carer, pursuing physical activities had a protective beneficial impact on their mental health over and above that observed for non-carers. This finding suggests that designing tailored therapeutic physical activity interventions should be considered to improve carers' mental health, and may also support their overall general health [58].

As expected, the results revealed that when people were non-carers, any level of alcohol consumption was harmful for their mental health, while a high level of alcohol consumption was harmful for their general health. However, one intriguing finding of this research was that some level of social drinking had a beneficial modifying impact on both mental and general health when people served as carers. This finding runs counter to non-carer drinking behaviours' effects on health. Previous research supports that caregivers who experience social and emotional burden related to caregiving are at risk for problematic alcohol use that may need mental health and public health support $[59,60]$. However, there is also evidence that carers, sometimes, take alcohol in order to forget their burden of caregiving and get some relief as a coping strategy. For that reason, some level of social drinking may have beneficial health effects on them $[59,60]$. While our research suggests, with caution, that social drinking may be promoted as a therapeutic intervention to support carer health, we also identify the need for further research to better understand the link between carer social drinking habits and their health.

Further, this research supported that smoking had a negative impact on non-carers' mental and general health while the effect was even worse when people served as carers. For carers, the results suggested that light (smoke less often than weekly) and medium (smoke at least weekly (but not daily)) smoking were more detrimental to mental health than daily smoking. This led to our assertion that smoking here may have been used as a coping mechanism as there is previous evidence that smoking is used as a coping mechanism for psychological stress [61].

\section{Social engagement, employment and Carer health}

Literature on carer's employment status and health have identified that high intensity caregiving does not go well with full-time employment in Australia or even allows no-workforce engagement such as in Japan [22, 25]. However, this study found no significant modifying 
impact of employment on carers' health. Furthermore, in a separate model, when we included high-intensity and low-intensity caregiving categories based on their caregiving hours and interacted that with carer employment participation, we found no modifying impact either on their mental or general health.

In line with previous literature, this research found that social interaction and community participation had significant positive impacts on non-carers mental and general health $[27-30,62]$. However, we did not find any significant attenuation effect of these activities on health when people served as carers. Whilst we found that social interactions (not significant) might not be beneficial for carers' mental health on a daily/weekly basis, they might prove beneficial when considered on a monthly/quarterly basis.

\section{Summarizing the discussion}

To sum up, this study added value to the literature on informal carers' mental and general health in Australia by identifying potential protective and risk factors. Using 11 waves of HILDA data and FE regression approach with panel-robust standard errors, the study found modifying effects of carers' health behaviours such as physical activity, smoking and drinking status while handling the issue of individuals self-selecting themselves as carers due to some predisposing factors such as socioeconomic status and sedentary behaviours. More importantly, the protective effects of physical activity and the possible benefits of socialising with alcohol (although this is not supported by the findings around social contacts with family and friends) need to be highlighted with caution for designing potential interventions.

Previous research found carers showing better fitness outcomes on specific components of their physical functioning than others [11]. We conducted separate analysis of carer physical functioning but found no evidence of a relation between caregiving status and physical functioning level.

The strength of this study lies in applying advanced econometric/statistical techniques to the already existing longitudinal, data set (HILDA). The study used a retrospective longitudinal design and the "fixed-effects" modelling approach that allowed to net out the effects of caregiving outcomes over the lifetime of an individual while adjusting for other time-variant potential confounders. The weaknesses include the observational nature of the survey data as opposed to controlled randomized design and the use of individual level characteristics only in the FE regression while there may be contextual variables shaping individual trajectories of mental and general health outcomes. Also, there may be issues with potentially low representativeness of the study sample to Australian population. Being a longitudinal study design, the response rates in the study would be low compared to cross-sectional surveys and decline with time due to attrition. It is highly likely that certain groups of the Australian population such as immigrants, Culturally and Linguistically Diverse (CALD) communities and low socio-economic status families may have low representation in the survey. Another limitation is the use of self-reported information such as caregiving status and outcome variables such as SF-36 mental and general health variables. The SF-36 mental health $(\mathrm{SF} 36 \mathrm{MH})$ and general health (SF36GH) have been widely used and extensively validated with reported excellent psychometric properties, although they may not necessarily be validated for Australian migrant or CALD subpopulations.

\section{Conclusion}

This study has made some notable contributions in understanding the health of Australian informal carers. The research indicates that poorer mental and general health profile of carers compared to non-carers in Australia can potentially be improved through targeted support programs for young carers. Additionally, targeted physical activity intervention programs may have beneficial mental health effects on carers. The potential link between moderate level of social drinking and carer health identified needs to be further explored with more targeted future research. Studies like this and suggested interventions would help care recipients and the greater society. Indeed, improved carer health may help to reduce the formal/institutional demand for carers and could bridge the gap in carers demand and supply.

\section{Abbreviations}

ADL: Activities of Daily Living; CALD: Culturally and Linguistically Diverse:

FE: Fixed Effects; HILDA: Household Income and Labour Dynamics of

Australia; IQOLA: International Quality of Life Assessment; RE: Random Effects; SCQ: Self-completion Questionnaire; SD: Standard Deviation; SF-36: Short

Form 36 Questionnaire; SF36GH: SF-36 General Health; SF36MH: SF-36 Mental Health

\section{Acknowledgments \\ This paper uses unit record data from the Household, Income and Labour Dynamics in Australia (HILDA) Survey. The HILDA survey was initiated and funded by the Australian Government Department of Social Services (DSS), and managed by the Melbourne Institute of Applied Economic and Social Research (Melbourne Institute; https://melbourneinstitute.unimelb.edu.au/ hilda). The findings and views reported in this paper, however, are those of the authors and should not be attributed to either the Australian Government, DSS or any of DSS' contractors or partners.}

\section{Authors' contributions}

IM and TN conceived and designed the research project. IM undertook initial statistical analyses of the data and drafted the manuscript. Both IM and TN contributed to the interpretation of results and revised the manuscript for important additional intellectual content. All the authors approved the final manuscript.

\section{Funding}

This research received no specific grant from any funding agency in the public, commercial or not-for-profit sectors. 


\section{Availability of data and materials}

This paper uses unit record data from the Household, Income and Labour Dynamics in Australia (HILDA) Survey. The HILDA survey data is one of the Australian Government Department of Social Services (DSS) longitudinal datasets housed by the National Centre for Longitudinal Data (NCLD) and managed by the Australian Data Archive (ADA). The datasets analysed and/ or generated during the current study are subject to the Confidentiality Deed signed with the Commonwealth of Australia (as represented by the Department of Social Services) and to the Commonwealth privacy laws. Data are accessible from the NCLD by application (https://www.dss.gov.au/ national-centre-for-longitudinal-data-ncld/access-to-dss-longitudinal-datasets), and any questions about applying for the DSS longitudinal datasets should be addressed to NCLD (ncld@dss.gov.au).

\section{Ethics approval and consent to participate}

This study requires no ethics approval for the authors as the analysis used only de-identified existing unit record data from the Household, Income and Labour Dynamics in Australia (HILDA) Survey. However, authors had completed and signed the Confidentiality Deed Poll and sent to NCLD (ncldresearch@dss.gov.au) and ADA (ada@anu.edu.au) before the data applications' approval. Therefore, datasets analysed and/or generated during the current study are subject to the signed confidentiality deed.

\section{Consent for publication}

Not Applicable.

\section{Competing interests}

The authors declare that they have no competing interests.

\section{Author details}

'Health Research Institute, Faculty of Health, University of Canberra, Canberra, Australian Capital Territory 2617, Australia. ${ }^{2}$ School of Health Sciences, University of South Australia, Adelaide 5001, Australia.

\section{Received: 12 June 2019 Accepted: 21 October 2019}

\section{Published online: 01 November 2019}

\section{References}

1. AlHW. Home and community care (HACC) data dictionary version 1.0: home and community care program National Minimum Data set. Canberra: AlHW; 1998

2. Economics DA. The economic value of informal care in Australia in 2015 Carers Australia 2015

3. AlHW. Carers in Australia: assisting frail older people and people with a disability. Australian Institute of Health Welfare (AlHW): Canberra; 2004.

4. AlHW. Australia's welfare 2015: Mental health of older Australians: Australian Institute of Health and Welfare (AlHW), 2015.

5. AlHW. Australia's welfare 2017: Australia's welfare series. Canberra: Australian Institute of Health and Welfare (AlHW). p. 2017.

6. Do T. InterGENERATIONAL REPORT; 2015.

7. Davis M. The Changing Nature of Marriage and Divorce. 2019. https://www. nber.org/digest/nov07/w12944.html (accessed 9th April 2019).

8. AIFS. Marriage and divorce rates: Australian Institute of family Studies (AIFS), 2019.

9. Productivity Commission A. Productivity Commission 2011. Caring for older Australians: overview, report no. 53, final inquiry report, vol. 2011. Canberra: Commonwelath of Australia.

10. Ory MG, Hoffman IIIRR, Yee JL, et al. Prevalence and impact of caregiving: a detailed comparison between dementia and nondementia caregivers. Gerontologist. 1999:39(2):177-86. https://doi.org/10.1093/geront/39.2.177.

11. Gusi N, Prieto J, Madruga $M$, et al. Health-related quality of life and fitness of the caregiver of patient with dementia. Med Sci Sports Exerc. 2009;41(6): $1182-7$.

12. Fredman $\mathrm{L}$, Bertrand RM, Martire LM, et al. Leisure-time exercise and overall physical activity in older women caregivers and non-caregivers from the caregiver-SOF study. Prev Med. 2006;43(3):226-9.

13. Pinquart $M$, Sörensen $S$. Gender differences in caregiver stressors, social resources, and health: an updated meta-analysis. J Gerontol Ser B Psychol Sci Soc Sci 2006;61(1):P33-P45.

14. Aneshensel CS, Pearlin LI, Mullan JT, et al. Profiles in caregiving: the unexpected career: Elsevier 1995.
15. Schulz R, Beach SR. Caregiving as a risk factor for mortality: the caregiver health effects study. Jama. 1999;282(23):2215-9.

16. Schulz R, Newsom J, Mittelmark M, et al. Health effects of caregiving: the caregiver health effects study: an ancillary study of the cardiovascular health study. Ann Behav Med. 1997;19(2):110-6.

17. Committee on Family Caregiving for Older Adults; Board on Health Care Services; Health and Medicine Division; National Academies of Sciences E, and Medicine. Families Caring for an Aging America. Washington (DC): National Academies Press (US); 2016.

18. Schulz R, Sherwood PR. Physical and mental health effects of family caregiving. J Soc Work Educ. 2008;44(sup3):105-13.

19. Son J, Erno A, Shea DG, et al. The caregiver stress process and health outcomes. J Aging Health. 2007;19(6):871-87.

20. Vitaliano PP, Zhang J, Scanlan JM. Is caregiving hazardous to one's physical health? A meta-analysis. Psychol Bull. 2003:129(6):946.

21. Vitaliano PP, Young HM, Zhang J. Is caregiving a risk factor for illness? Curr Dir Psychol Sci. 2004:13(1):13-6.

22. Kenny P, King MT, Hall J. The physical functioning and mental health of informal carers: evidence of care-giving impacts from an Australian population-based cohort. Health Soc Care Community. 2014;22(6):646-59.

23. Hajek $\mathrm{A}$, König $\mathrm{H}-\mathrm{H}$. The effect of intra-and intergenerational caregiving on subjective well-being-evidence of a population based longitudinal study among older adults in Germany. PLoS One. 2016;11(2):e0148916.

24. Penning MJ, Wu Z. Caregiver stress and mental health: impact of caregiving relationship and gender. Gerontologist. 2015;56(6):1102-13.

25. Kumagai N. Distinct impacts of high intensity caregiving on caregivers' mental health and continuation of caregiving. Heal Econ Rev. 2017;7(1):15.

26. Farrugia T, Hewitt A, Bourke-Taylor $\mathrm{H}$, et al. The impact of carer status on participation in healthy activity and self-reported health among Australian women over 50 years. Aust Occup Ther J. 2019;66(1):23-32.

27. Berry H. Subjective perceptions about sufficiency and enjoyment of community participation and associations with mental health. Australas Epidemiol. 2008:15(3):4-9.

28. Berry H, Rickwood D. Measuring social Capital at the Individual Level: personal social capital, values and psychological distress. J Public Ment Health. 2000;2(3):35-44.

29. Berry HL. Social capital and mental health among aboriginal Australians, new Australians and other Australians living in a coastal region. Aust e- $J$ Adv Ment Health. 2009:8(2):142-54.

30. Berry HL, Welsh JA. Social capital and health in Australia: an overview from the household, income and labour dynamics in Australia survey. Soc Sci Med. 2010;70(4):588-96

31. Lee C, Gramotnev H. Transitions into and out of caregiving: health and social characteristics of mid-age Australian women. Psychol Health. 2007; 22(2):193-209.

32. Summerfield M, Bevitt A, Freidin S, Hahn M, La N, Macalalad N, O'Shea M, Watson N, Wilkins R, Wooden M. HILDA user manual - release 16 Melbourne Institute of Applied Economic and Social Research, University of Melbourne. 2017.

33. Watson N, Wooden M. Factors affecting response to the HILDA survey selfcompletion questionnaire. In: Melbourne Uo, ed. Melbourne: Melbourne Institute of Applied Economic and Social Research, University of Melbourne: 2015.

34. Ware JE. Scoring the SF-36. In: SF-36 Health Survey: Manual and Interpretation Guide; 1993

35. Ware JE Jr, Gandek B. Methods for testing data quality, scaling assumptions, and reliability: the IQOLA project approach. J Clin Epidemiol. 1998;51(11): $945-52$.

36. Sullivan M, Karlsson J, Ware JE Jr. The Swedish SF-36 health survey-1. evaluation of data quality, scaling assumptions, reliability and construct validity across general populations in Sweden. Soc Sci Med. 1995;41(10): 1349-58.

37. Torres-Reyna O. Panel data analysis fixed and random effects using Stata (v. 4.2). Data \& Statistical Services, Priceton University. 2007.

38. Brüderl J, Ludwig V. Fixed-effects panel regression. Sage Handb Regression Anal Causal Inference. 2015:327-57.

39. Greene WH. Fixed and random effects models for count data; 2007.

40. Greene WH. Econometric analysis. 6th ed. Englewood Cliffs: Prentice Hall; 2008

41. Hausman JA. Specification tests in econometrics. Econometrica J Econometric Soc. 1978:1251-71. 
42. Chmelarova V. The Hausman test, and some alternatives, with heteroskedastic data. Louisiana State University \& Agricultural \& Mechanical College. 2007

43. Carroll SJ, Paquet C, Howard NJ, et al. Local descriptive body weight and dietary norms, food availability, and 10-year change in glycosylated haemoglobin in an Australian population-based biomedical cohort. BMC Public Health. 2017;17(1):149.

44. Montoya AK. Moderation analysis in two-instance repeated measures designs: probing methods and multiple moderator models. Behav Res Methods. 2019;51(1):61-82.

45. Cameron AC, Miller DL. A practitioner's guide to cluster-robust inference. J Hum Resour. 2015;50(2):317-72.

46. StataCorp L. Stata statistical software (version release 14). College Station: Author; 2015.

47. McCaffrey DF, Lockwood JR, Mihaly K, et al. A review of Stata commands for fixed-effects estimation in normal linear models. Stata J. 2012;12(3):406.

48. Saxena S, Funk M, Chisholm D. WHO's mental health action plan 2013-2020: what can psychiatrists do to facilitate its implementation? World Psychiatry. 2014;13(2):107-9

49. AlHW. Australia's welfare 2015. In: Australia's welfare series Canberra: Australian Institute of Health and Welfare (AlHW). p. 2015.

50. AlHW. Australia's welfare 2015. In: Informal carers. Canberra: Australian Institute of Health and Welfare (AlHW). p. 2015.

51. ABS. Disability, ageing and carers, Australia: Summary of findings, 2012. In: Canberra: Australian Bureau of Statistics (ABS). p. 2013.

52. Cass B, Smith C, Hill T, et al. Young carers in Australia: understanding the advantages and disadvantages of their care giving. FaHCSIA Social Policy Research Paper. 2009;38.

53. Cass B, Brennan D, Thomson C, et al. Young carers: social policy impacts of the caring responsibilities of children and young adults. 2011.

54. Carroll SJ, Niyonsenga T, Coffee NT, et al. Does physical activity mediate the associations between local-area descriptive norms, built environment walkability, and glycosylated hemoglobin? Int J Environ Res Public Health. 2017;14(9):953.

55. Thompson PD, Buchner D, Piña IL, et al. Exercise and physical activity in the prevention and treatment of atherosclerotic cardiovascular disease: a statement from the council on clinical cardiology (subcommittee on exercise, rehabilitation, and prevention) and the council on nutrition, physical activity, and metabolism (subcommittee on physical activity). Circulation. 2003;107(24):3109-16.

56. Warburton DE, Nicol CW, Bredin SS. Health benefits of physical activity: the evidence. Can Med Assoc J. 2006;174(6):801-9.

57. Penedo FJ, Dahn JR. Exercise and well-being: a review of mental and physical health benefits associated with physical activity. Curr Opin Psychiatry. 2005;18(2):189-93.

58. Cothran FA, Paun O, Barnes $L L$, et al. Comparing the effect of a moderate physical activity intervention on the mental health outcomes of African American and Caucasian dementia family caregivers: a secondary data analysis. Issues Ment Health Nurs. 2017;38(12):996-1004.

59. Rospenda KM, Minich LM, Milner LA, et al. Caregiver burden and alcohol use in a community sample. J Addict Dis. 2010;29(3):314-24.

60. Jathanna RP, L KS, Bhandary P. Burden and coping in informal caregivers of persons with dementia: a cross sectional study. Online J Health Allied Sci. 2011:9(4).

61. Slopen N, Kontos EZ, Ryff CD, et al. Psychosocial stress and cigarette smoking persistence, cessation, and relapse over 9-10 years: a prospective study of middle-aged adults in the United States. Cancer Causes Control. 2013;24(10):1849-63.

62. Oshio T, Kan M. How do social activities mitigate informal caregivers' psychological distress? Evidence from a nine-year panel survey in Japan. Health Qual Life Outcomes. 2016;14(1):117.

\section{Publisher's Note}

Springer Nature remains neutral with regard to jurisdictional claims in published maps and institutional affiliations.

\section{Ready to submit your research? Choose BMC and benefit from:}

- fast, convenient online submission

- thorough peer review by experienced researchers in your field

- rapid publication on acceptance

- support for research data, including large and complex data types

- gold Open Access which fosters wider collaboration and increased citations

- maximum visibility for your research: over $100 \mathrm{M}$ website views per year

At BMC, research is always in progress.

Learn more biomedcentral.com/submissions 